\title{
CARA PERSALINAN DAN TERJADINYA KOMPLIKASI PERSALINAN BERDASARKAN TINGKAT RISIKO KEHAMILAN MENURUT SKOR POEDJI ROCHJATI DI PRAKTIK MANDIRI BIDAN F BANJARMASIN
}

\author{
Nur Lathifah $^{1 *}$, Fitri Yuliana ${ }^{2}$ \\ ${ }^{1}$ UNISM, Fakultas Humaniora \\ ${ }^{2}$ UNISM, Fakultas Kesehatan
}

*Korespondensi Penulis: Telp: 085754865555, e-mail: ifa_mid@yahoo.com

DOI: https://doi.org/10.33859/dksm.v10i2.509

\begin{abstract}
ABSTRAK
Latar Belakang: Salah satu cara untuk menurunkan angka kesakitan dan kematian ibu dengan pendekatan risiko pada ibu hamil. Deteksi risiko dapat dilakukan oleh bidan dengan skor Poedji Roechayati. Di praktik Mandiri Bidan (PMB) F hal ini telah dilaksanakan. Berdasarkan data terakhir pada bulan Mei 2019, dari 48 orang ibu hamil yang berkunjung ke PMB F didapatkan 18 orang $(37,5 \%)$ kelompok risiko tinggi (KRT) dan 3 orang $(6,25 \%)$ kelompok risiko sangat tinggi (KRST), di tahun 2018 , terdapat $21 \%$ kasus komplikasi persalinan.

Tujuan: Menganalisa hubungan antara tingkat risiko ibu hamil dengan kejadian komplikasi persalinan dan juga cara persalinannya.

Metode: . Metode penelitian kuantitatif dengan rancangan penelitian Cross Sectional. Populasi penelitian ini adalah semua ibu bersalin di PMB F pada tahun 2017 s.d juni 2019 sebanyak 90 orang dengan tehnik sampling jenuh. Data dianalisis menggunakan uji Chi Squere.

Hasil: Dari 90 orang sampel yang diteliti 60 orang $(66,7 \%)$ yang termasuk kelompok ibu hamil risiko tinggi (KRT). Ibu dengan cara persalinan normal sebanyak 73 orang $(81,1 \%)$. Ibu yang mengalami komplikasi pada saat persalinan sebanyak 32 orang $(35,6 \%)$ dari 90 sampel dan komplikasi ini banyak terjadi pada kelompok risiko tinggi ( 23 orang) dan kelompok risiko sangat tinggi ( 7 orang).

Simpulan: Ada hubungan yang signifikan antara Komplikasi persalinan dengan tingkat risiko ibu hamil dan tidak ada hubungan cara persalinan dengan tingkat risiko ibu hamil.
\end{abstract}

Kata Kunci: Cara Persalinan, Komplikasi Persalinan, Tingkat Risiko Kehamilan 
Background: One way to reduce maternal morbidity and mortality with a risk approach for pregnant women. Risk detection can be done by midwives with Poedji Roechayati scores. In practice the Mandiri Midwife (PMB) F this has been carried out. Based on the latest data in May 2019, out of 48 pregnant women visiting $P M B F$, there were 18 people (37.5\%) high risk group (KRT) and 3 people (6.25\%) very high risk group (KRST), in 2018, there were $21 \%$ of cases of childbirth complications.

Objective: To analyze the relationship between the risk level of pregnant women with the incidence of labor complications and also the mode of delivery.

Method: . Quantitative research methods with cross sectional research design. The population of this study were all women giving birth at PMB F in 2017 to June 2019, as many as 90 people with saturated sampling techniques. Data were analyzed using the Chi Squere test.

Results: Of the 90 samples studied, 60 (66.7\%) were included in the high risk group of pregnant women (KRT). Mothers by normal delivery were 73 people (81.1\%). Mothers who experienced complications at the time of delivery were 32 people (35.6\%) from 90 samples and this complication mostly occurred in the high risk group (23 people) and the very high risk group (7 people).

Conclusion: There is a significant relationship between the complications of childbirth with the level of risk of pregnant women and there is no relationship between the way of delivery and the risk of pregnant women.

Keywords: Delivery Method, Labor Complications, Pregnancy Risk Level

\section{PENDAHULUAN}

Berbagai upaya dilakukan untuk

membantu menurunkan angka kematian ibu, termasuk upaya mengurangi komplikasi kehamilan dan persalinan. Diperkirakan 15\% $20 \%$ kehamilan dan persalinan akan mengalami komplikasi. Sebagian komplikasi ini dapat mengakibatkan kematian ibu dan janin. Namun sebagian besar komplikasi dapat dicegah. Salah satu cara yang efektif untuk memantau adanya komplikasi kehamilan dan persalinan adalah dengan deteksi ini kehamilan berisiko tinggi (Senewe, 2004).
Komplikasi persalinan merupakan penyebab langsung dari kesakitan dan kematian pada maternal. Hal ini disebabkan karena proses persalinan dihadapkan pada kondisi kritis terhadap masalah kegawatdaruratan sehingga salah satu upaya untuk mengantisipasi risiko yang akan terjadi dengan mendeteksi faktor risiko secara dini (Hidayah, 2018).

Menurut hasil penelitian analisis lanjut data sekunder Riskesdas 2010, menunjukkan 
Dinamika Kesehatan Jurnal Kebidanan dan Keperawatan Vol 10 No. 1 Juli 2019 ( ISSN: 2086-3454 EISSN: 2549-4058)

url: http://ojs.dinamikakesehatan.unism.ac.id DOI : https://doi.org/10.33859/dksm.v10i2

Cara Persalinan Dan Terjadinya Komplikasi Persalinan Berdasarkan Tingkat Risiko Kehamilan Menurut Skor Poedji Rochjati Di Praktik Mandiri Bidan F Banjarmasin

proporsi kejadian komplikasi persalinan di Indonesia antara kurun waktu tahun 2005-2010 sebanyak 47,8 persen. Hasil determinan kejadian komplikasi adalah : faktor status reproduksi yaitu paritas satu atau lebih sama dengan empat anak, jarak kelahiran dan adanya komplikasi kehamilan, faktor akses pelayanan kesehatan yaitu wilayah tempat tinggal dan informasi komplikasi kehamilan dan persalinan, faktor pemanfaatan pelayanan kesehatan yaitu kunjungan pemeriksaan antenatal minimal empat kali, pemilihan penolong persalinan pada tenaga kesehatan dan pemilihan tempat persalinan. (Simarmata, dkk, 2014). Dan faktor yang paling dominan berhubungan dengan kejadian komplikasi persalinan adalah riwayat komplikasi kehamilan (Rizkinauli, 2016)

Komplikasi kehamilan berkaitan dengan kehamilan risiko tinggi. Kehamilan Risiko Tinggi merupakan salah satu kehamilan yang di dalamnya kehidupan atau kesehatan ibu atau janin dalam bahaya akibat gangguan kehamilan. Kriteria yang dikemukakan oleh peneliti-peneliti dari berbagai institut berbeda- beda, namun dengan tujuan yang sama mencoba mengelompokkan kasus-kasus risiko tinggi. Salah satu cara skoring ibu hamil berisiko tinggi yang sering digunakan di Indonesia adalah skor poedji Rochjati.

Skrining ibu hamil berisiko dengan menggunakan kartu skor poedi Rochjati digunakan bukan hanya di tempat pelayanan kesehatan masyarakat milik pemerinta juga di gunakan pada tempat pelayanan mandiri yang dikelola oleh bidan. Termasuk Praktik mandiri bidan " $F$ " juga telah mengunakan skor poedji Rochjati sejak tahun 2016 untuk deteksi adanya risiko pada ibu hamil yang berkunjung.

Berdasarkan data terakhir pada bulan Mei 2019, dari 48 orang ibu hamil yang berkunjung ke praktik mandiri bidan (PMB) F didapatkan 27 orang $(56,2 \%)$ kelompok risiko rendah (KRR), 18 orang $(37,5 \%)$ kelompok risiko tinggi (KRT) dan 3 orang (6,25\%) kelompok risiko sangat tinggi (KRST). Berdasarkan data PMB F tahun 2018, terdapat 21\% kasus komplikasi persalinan yang terjadi dan semua dilakukan rujukan ke rumah sakit, sebagian 
Dinamika Kesehatan Jurnal Kebidanan dan Keperawatan Vol 10 No. 1 Juli 2019 ( ISSN: 2086-3454 EISSN: 2549-4058)

url: http://ojs.dinamikakesehatan.unism.ac.id DOI : https://doi.org/10.33859/dksm.v10i2

Cara Persalinan Dan Terjadinya Komplikasi Persalinan Berdasarkan Tingkat Risiko Kehamilan Menurut Skor Poedji Rochjati Di Praktik Mandiri Bidan F Banjarmasin

bersalin pervaginam dan sebagian persalinan dengan tindakan.

\section{BAHAN DAN METODE}

Metode penelitian ini menggunakan Analitik dengan pendekatan Cross Sectional. Populasi dalam penelitian ini adalah semua ibu yang hamil dan bersalin yang terdata di PMB F sejak Januari 2017 s.d Juni 2019 sebanyak 90 orang sedangkan sampel penelitian ini diambil secara Total Sampling sebanyak 90 orang.

Analisis data pada penelitian ini menggunakan analisa univariat terhadap tiap variabel. Sedangkan untuk analisa biavariat dengan uji chi square, dan sebagai alternatif maka digunakan uji Kolmogorov Smirnov.

\section{HASIL}

\section{Analisis Univariat}

1. Tingkat Risiko Kehamilan

Tabel 1 Distribusi frekuensi Tingkat Risiko Kehamilan di PMB F tahun 2017 s.d juni 2019.

\begin{tabular}{|c|c|c|c|c|}
\hline \multicolumn{3}{|c|}{$\begin{array}{c}\text { Kategori Tingkat Risiko } \\
\text { Kehamilan }\end{array}$} & $\begin{array}{c}\text { Frekuensi } \\
\text { (Orang) }\end{array}$ & $\begin{array}{c}\text { Persentase } \\
(\%)\end{array}$ \\
\hline $\begin{array}{l}1 . \\
2 . \\
3 .\end{array}$ & $\begin{array}{l}\text { Kehamilan } \\
\text { Rendah (KRR) } \\
\text { Kehamilan } \\
\text { Tinggi (KRT) } \\
\text { Kehamilan } \\
\text { Sangat Tinggi (K }\end{array}$ & $\begin{array}{l}\text { Risiko } \\
\text { Risiko } \\
\text { RST) }\end{array}$ & $\begin{array}{l}20 \\
60 \\
10\end{array}$ & $\begin{array}{l}22,2 \\
66,7 \\
11,1\end{array}$ \\
\hline & Jumlah & & 90 & 100 \\
\hline
\end{tabular}

Tabel 1 menunjukkan ibu hamil dengan kategori kehamilan risiko tinggi (KRT) merupakan jumlah terbanyak yaitu 60 orang $(66,7 \%)$ yang paling sedikit adalah ibu hamil dengan risiko sangat tinggi (KRST) sebanyak 10 orangan $(11,1 \%)$.

2. Cara Persalinan

Tabel 2 Distribusi frekuensi Cara Persalinan di PMB F Tahun tahun 2017 s.d juni 2019.

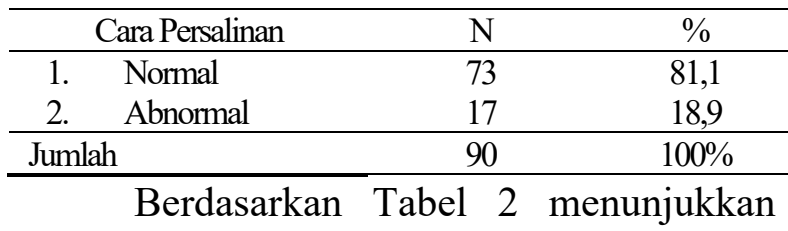

distribusi frekuensi 90 sampel yang diteliti, jumlah sampel yang terbanyak mengalami cara persalinan normal sebanyak 73 orang $(81,1 \%)$

3. Kejadian Komplikasi Persalinan

$$
\begin{array}{lllr}
\text { Tabel } & 3 \text { Distribusi frekuensi } & \text { Cara } \\
& \text { Persalinan di PMB F Tahun } \\
& \text { tahun } 2017 \text { s.d juni 2019. }
\end{array}
$$

\begin{tabular}{llcc}
\hline \multicolumn{2}{l}{ Komplikasi Persalinan } & $\mathrm{N}$ & $\%$ \\
\hline 1. Ada & 32 & 35,6 \\
2. Tidak Ada & 58 & 64,4 \\
\hline Jumlah & 90 & $100 \%$ \\
\hline
\end{tabular}

Pada tabel 3 menunjukkan dari 90 sampel yang diteliti, jumlah sampel yang terbanyak tidak mengalami komplikasi yaitu sebanyak 58 orang $(64,4 \%)$. 


\section{Analisis Bivariat}

1. Cara Persalinan Berdasarkan Tingkat Risiko Kehamilan

Tabel 4 Hubungan Tingkat Risiko Kehamilan dengan Cara Persalinan Pada Ibu Hamil dan Bersalin di PMB F Tahun 2017 s.d Juni 2019

\begin{tabular}{cccccccc}
\hline \multirow{2}{*}{$\begin{array}{c}\text { Tingkat } \\
\text { Risiko }\end{array}$} & \multicolumn{4}{c}{ Cara Persalinan } & Jumlah & $\mathrm{p}$ \\
\cline { 2 - 5 } & \multicolumn{2}{c}{ Normal } & \multicolumn{3}{c}{ Abnormal } & & \\
\cline { 2 - 6 } & $\mathrm{f}$ & $\%$ & $\mathrm{f}$ & $\%$ & $\mathrm{f}$ & $\%$ & \\
\hline KRR & 19 & 95,0 & 1 & 5,0 & 20 & 100 & $\rho=$ \\
\hline KRT & 49 & 81,7 & 11 & 18,3 & 60 & 100 & 0,48 \\
\hline KRST & 5 & 50 & 5 & 50 & 10 & 100 & \\
\hline
\end{tabular}

Berdasarkan Tabel 4 dapat dilihat bahwa pada kelompok ibu dengan kehamilan risiko rendah lebih banyak bersalin normal yaitu 19 orang $(95,0 \%)$, sedangkan pada kehamilan risiko tinggi lebih banyak yang bersalin normal yaitu 49 orang $(81,5 \%)$, sedangkan pada kehamilan risiko sangat tinggi 5 orang $(50 \%)$ yang bersalin normal dan 5 orang $(50 \%)$ yang bersalin abnormal.

Setelah dilakukan analisa hubungan antara tingkat risiko kehamilan dan kejadian cara persalinan dengan uji chi squere tidak memenuhi syarat karena banyak cel yang memiliki nilai ekspektasi kurang dari 5\%, kemudian dilakukan uji Colmogorav didapatkan nilai $\rho=0,48>\alpha=0,05$ maka dapat disimpulkan Tidak ada hubungan yang signifikan antara Tingkat Risiko Kehamilan dan Cara Persalinan.

2. Komplikasi Persalinan Berdasarkan Tingkat Risiko Kehamilan

Tabel 5 Hubungan Tingkat Risiko Kehamilan dengan Komplikasi Persalinan Pada Ibu Hamil dan Bersalin di PMB F Tahun 2017 s.d Juni 2019

\begin{tabular}{cccccccc}
\hline Tingkat & \multicolumn{4}{c}{ Komplikasi Persalinan } & \multicolumn{2}{c}{ Jumlah } & $\mathrm{p}$ \\
\cline { 2 - 5 } Risiko & \multicolumn{2}{c}{ Ada } & \multicolumn{2}{c}{ Tidak Ada } & & & \\
& $\mathrm{f}$ & $\%$ & $\mathrm{f}$ & $\%$ & $\mathrm{f}$ & $\%$ & \\
\cline { 2 - 7 } KRR & 2 & 10,0 & 18 & 90,0 & 20 & 100 & $\rho$ \\
KRT & 23 & 38,3 & 37 & 61,7 & 60 & 100 & \\
KRST & 7 & 70 & 3 & 30 & 10 & 100 & \\
\hline
\end{tabular}

Berdasarkan Tabel 5 dapat dilihat bahwa

pada kelompok ibu dengan kehamilan risiko rendah lebih banyak yang tidak mengalami komplikasi persalinan yaitu 18 orang $(90,0 \%)$, sedangkan pada kehamilan risiko tinggi lebih banyak yang tidak mengalami komplikasi persalinan, tetapi dari segi prosentase lebih rendah dari yang risiko rendah, yaitu 37 orang (61,7\%), sedangkan pada kehamilan risiko sangat tinggi lebih banyak yang mengalami komplikasi yaitu 7 orang (70\%).

Setelah dilakukan analisa hubungan antara tingkat risiko kehamilan dan kejadian komplikasi persalinan dengan uji chi squere didapatkan nilai $\rho=0,004<\alpha=0,05$ maka dapat 
Dinamika Kesehatan Jurnal Kebidanan dan Keperawatan Vol 10 No. 1 Juli 2019 ( ISSN: 2086-3454 EISSN: 2549-4058)

url: http://ojs.dinamikakesehatan.unism.ac.id DOI : https://doi.org/10.33859/dksm.v10i2

Cara Persalinan Dan Terjadinya Komplikasi Persalinan Berdasarkan Tingkat Risiko Kehamilan Menurut Skor Poedji Rochjati Di Praktik Mandiri Bidan F Banjarmasin

disimpulkan ada hubungan yang signifikan antara Tingkat Risiko Kehamilan dan Kejadian Komplikasi Persalinan.

\section{PEMBAHASAN}

1. Tingkat Risiko Kehamilan

Tingkat risiko kehamilan dalam penelitian ini didapatkan dari skor Poeji Rochjati, yang mengelompokkan ibu hamil dalam tiga tingkatan, yaitu ibu hamil dengan risiko rendah, risiko tinggi dan sangat tinggi. Pada penelitian ini, dari 90 orang sampel, kehamilan risiko tinggi (KRT) merupakan jumlah terbanyak yaitu 57 orang $(63,1 \%)$ dan yang paling sedikit adalah ibu hamil dengan risiko sangat tinggi (KRST) sebanyak 10 orangan (11,1\%). Jika melihat dari hasil penelitian ini ibu yang tergolong pada kehamilan risiko tinggi dan risiko sangat tinggi lebih banyak dari pada ibu hamil dengan risiko rendah (KRR).

Kehamilan risiko tinggi (KRT) mempunyai skor antara $6-10$, atau memiliki satu atau dua factor risiko. Sedangkan Kehamilan risiko sangat tinggi (KRST) mempunyai skor lebih dari atau sama dengan 12, atau memiliki lebih dari dua faktor risiko.

Skor Poeji Rochjati dalam deteksi risiko tinggi ibu hamil ini merupakan salah satu bentuk dari pendekatan faktor risiko yang digunakan dalam obstetric modern saat ini. Tujuan Pendekatan risiko ini untuk meningkatkan mutu pelayanan kepada semua ibu hamil, janin dan bayi baru lahir sebagai suatu kesatuan, tetapi juga memberikan perhatian khusus dan lebih intensif diberikan kepada mereka yang mempunyai peluang lebih besar terjadinya risiko (rochjati, 2013). Begitupun yang telah dilakukan di PMB F, deteksi ibu hamil berisiko telah dilakukan, dan didapatkan ibu hamil dengan risiko tinggi dan sangat tinggi jumlahnya lebih banyak dibandingkan kelompok ibu hamil risiko rendah. Hal ini menuntut tim di PMB $F$ untuk meningkatkan mutu layanan, memberikan perhatian lebih pada kelompok yang berisiko tinggi dan sangat tinggi agar tidak terjadi kegawatdaruratan yang mengalami keterlambatan. 
Dinamika Kesehatan Jurnal Kebidanan dan Keperawatan Vol 10 No. 1 Juli 2019 ( ISSN: 2086-3454 EISSN: 2549-4058)

url: http://ojs.dinamikakesehatan.unism.ac.id DOI : https://doi.org/10.33859/dksm.v10i2

Cara Persalinan Dan Terjadinya Komplikasi Persalinan Berdasarkan Tingkat Risiko Kehamilan Menurut Skor Poedji Rochjati Di Praktik Mandiri Bidan F Banjarmasin

Pada penelitian ini, faktor risiko yang paling banyak terjadi adalah penyakit yang menyertai ibu yaitu kurang darah (anemia). Anemia yang dimaksudkan adalah kondisi haemoglobin darah ibu hamil kurang dari $11 \mathrm{gr} \%$, hal ini sesuai dengan kriteria dari WHO, namun pada sampel yang diteliti, kondisi anemia yang dialami ibu hamil tidak ada anemia berat. Kejadian anemia pada sampel penelitian ini sebanyak $54,4 \%$ dari 90 ibu hamil, angka ini lebih tinggi dari kejadian anemia pada ibu hamil di tingkat nasional pada hasil RISKESDES 2013, yaitu sebanyak 37,1\% (Deprika, 2017). Penyebab tingginya angka kejadian anemia di PMB F ini masih belum bisa dipastikan karena untuk menjadwab hal ini memerlukan penelitian lebih lanjut, namun yang perlu digarisbawahi, walaupun ibu hamil pada sampel ini banyak yang mengalami anemia, namun hanya anemia ringan sampai dengan anemia sedang saja, dan data pemeriksaan HB yang di gunakan pada skor ibu hamil ini adalah hasil pemeriksaan di trimester III. Pada perubahan fisiologis tubuh ibu hamil di trimeseter III terutama di umur kehamilan 32 minggu ke atas terjadi haemodilusi yang menyebabkan pengenceran darah sehingga ibu banyak yang mengalami anemia, apalagi jika tidak diimbangi dengan tambahan zat besi yang memadai. Di PMB F tempat penelitian ini telah memberikan tablet Fe pada semua ibu hamil, maksimal sejak umur kehamilan trimester II atau setelah mual muntah berkurang. Hal ini dilakukan untuk menekan kejadian anemia pada ibu hamil.

Faktor risiko lainnya yang banyak dialami oleh sampel penelitian adalah pernah gagal dalam kehamilan (riwayat Abortus), terlalu pendek, terlalu lama hamil lagi, terlalu tua umur saat hamil ini, dan terlalu banyak anak lebih dari 4 .

Faktok -faktor yang dialami oleh sampel penelitian ini masuk pada kelompok I dan II dari klasifikasi kegawatdaruratan pada ibu. Yang dimaksud dengan Kelompok I ini adalah kelompok ibu hamil dengan Ada Potensi Gawat 
Dinamika Kesehatan Jurnal Kebidanan dan Keperawatan Vol 10 No. 1 Juli 2019 ( ISSN: 2086-3454 EISSN: 2549-4058)

url: http://ojs.dinamikakesehatan.unism.ac.id DOI : https://doi.org/10.33859/dksm.v10i2

Cara Persalinan Dan Terjadinya Komplikasi Persalinan Berdasarkan Tingkat Risiko Kehamilan Menurut Skor Poedji Rochjati Di Praktik Mandiri Bidan F Banjarmasin

Obstetrik/APGO, artinya ibu ini memiliki masalah yang perlu diwaspadai, walaupun tidak ada keluhan yang membahayakan dan ibu sehat, tetapi perlu diwaspadai karena ada kemungkinan dapat terjadi komplikasi persalinan, yang termasuk dalam kelompok I adalah beberapa terlalu, seperti tertalu muda, terlalu tua, terlalu dekat, terlalu jauh.

Sedangkan Kelompok II adalah kelompok ibu hamil dengan Ada Gawat Obstetrik/AGO. Yang termasuk dalam kategori kelompok II ini seperti ibu dengan anemia, letak sungsang dan pre eklampsi ringan. Kelompok I dan II yang disebutkan tadi termasuk kelompok risiko tinggi, namun kelompok I dan II masih ada cukup waktu untuk mendapatkan penyuluhan/KIE agar ada kesiapan mental, biaya dan transportasi untuk rujukan terencana dalam upaya mendapatkan persalinan aman dan penanganan adekuat di rumah sakit rujukan (Rochjati, 2003).

2. Cara Persalinan Berdasarkan Tingkat Risiko Kehamilan
Salah satu tujuan deteksi ibu hamil risiko tinggi dengan skoring Poeji Rochjati adalah membuat pengelompokkan dari ibu hamil (KRR, KRT, KRST) agar berkembang perilaku kebutuhan tempat dan penolong persalinan sesuai dengan kondisi dari ibu hamil (Rochjati, 2003)

Pada penelitian ini kelompok risiko yang terbanyak adalah kehamilan risiko tinggi (KRT), sesuai dengan teori poedji rochjati, untuk kelompok KRT ini memerlukan penolong persalinan bidan atau dokter di polindes, puskesmas atau rumah sakit. Sedangkan cara persalinan sangat tergantung dari kondisi ibu.

Pada penelitian ini dari 90 sampel, sebagian besar melahirkan secara normal (73 orang atau 81,1 \%), jika dilihat berdasarkan tingkat risiko kehamilan, ibu dengan dengan kehamilan risiko rendah lebih banyak bersalin normal yaitu 22 orang $(95,7 \%)$, pada kehamilan risiko tinggi lebih banyak yang bersalin normal, yaitu 47 orang $(82,5 \%)$, sedangkan pada kehamilan risiko sangat tinggi 5 orang $(50 \%)$ yang 
Dinamika Kesehatan Jurnal Kebidanan dan Keperawatan Vol 10 No. 1 Juli 2019 ( ISSN: 2086-3454 EISSN: 2549-4058)

url: http://ojs.dinamikakesehatan.unism.ac.id DOI : https://doi.org/10.33859/dksm.v10i2

Cara Persalinan Dan Terjadinya Komplikasi Persalinan Berdasarkan Tingkat Risiko Kehamilan Menurut Skor Poedji Rochjati Di Praktik Mandiri Bidan F Banjarmasin

bersalinan normal dan 5 orang $(50 \%)$ yang bersalin abnormal.

Dilihat dari angka tersebut menunjukkan walaupun ibu dalam kelompok risiko tinggi namun tetap dapat melahirkan normal. Namun Persalinan tetap dilakukan di tempat dan penolong yang aman. Seperti pada ibu hamil berisiko sangat tinggi (KRST) sebanyak 50\% melahirkan normal namun persalinan dilakukan di rumah sakit untuk menghindari kemungkinan terjadi komplikasi persalinan.

Setelah dilakukan analisa hubungan antara tingkat risiko kehamilan dan kejadian cara persalinan nilai $\rho=0,40>$ $\alpha=0,05$ maka dapat disimpulkan Tidak ada hubungan yang signifikan antara Tingkat Risiko Kehamilan dan Cara Persalinan. Tidak selalu kasus ibu hamil dengan risiko tinggi dan sangat tinggi akan melahirkan abnormal dan sebaliknya tidak selalu kasus ibu hamil dengan risiko rendah akan melahirkan normal. Sehingga semua ibu dan keluarga perlu diberikan edukasi tentang perencanaan persalinan yang aman serta adanya kemungkinan kegawatdaruratan yang terjadi tiba tiba. Dengan perencanaan persalinan yang baik maka ibu dapat terhindar dari kondisi gawatdarurat yang mengharuskan tindakan persalinan dengan section caesaria, sebagai contoh ibu hamil dengan tekanan darah tinggi, dengan penanganan yang cepat dan rujukan dini terencana, ibu hamil tersebut dapat bersalinan normal pervaginam tanpa mengalami komplikasi.

3. Kejadian Komplikasi Persalinan Berdasarkan Tingkat Risiko Kehamilan

Dari penelitian ini didapatkan hasil, bahwa ibu hamil dengan tingkat risiko rendah hanya sebagian kecil yang mengalami komplikasi dalam persalinan. Sebaliknya, ibu hamil yang mempunyai tingkat risiko sangat tinggi, sebagian besar mendapatkan komplikasi pada saat persalinan. Berdasarkan hasil analisa korelasi antara tingkat risiko kehamilan dan kejadian komplikasi persalinan dengan uji 
chi squere didapatkan nilai $\rho=0,004<$ $\alpha=0,05$ yang berarti ada hubungan yang signifikan antara Tingkat Risiko Kehamilan dan Kejadian Komplikasi Persalinan.

Hasil penelitian ini sama dengan hasil penelitian Prima Hidayah dkk, pada akhir tahun 2016, yang berjudul Hubungan Tingkat Risiko Kehamilan dengan Kejadian Komplikasi Persalinan di RSUD Panembahan Senopati Bantul, yang hasilnya menyimpulkan ada hubungan antara tingkat risiko kehamilan dengan kejadian komplikasi persalinan.

Penelitian ini juga sejalan dengan penelitian yang telah dilakukan oleh Oster Suriani Simarmata tentang analisis lanjut data sekunder Riskedas 2010 yang mengidentifikasi determinan kejadian komplikasi persalinan di Indonesia. Tujuan dari analisis ini adalah untuk mengkaji determinan yang berhubungan dengan kejadian komplikasi persalinan 5 tahun terakhir di Indonesia. Hasil penelitian menunjukkan proporsi kejadian komplikasi persalinan di Indonesia antara kurun waktu tahun 2005-2010 sebanyak 47,8 persen.

Hasil determinan kejadian komplikasi adalah: faktor status reproduksi yaitu paritas satu atau lebih sama dengan empat anak, jarak kelahiran dan adanya komplikasi kehamilan, faktor akses pelayanan kesehatan, faktor pemanfaatan pelayanan kesehatan, pemilihan penolong persalinan pada tenaga kesehatan dan pemilihan tempat persalinan. Dan faktor yang paling dominan berhubungan dengan kejadian komplikasi persalinan adalah riwayat komplikasi kehamilan.

Faktor yang disebutkan sebagai determinan pada hasil penelitian Simarmata, merupakan faktor risiko yang diketahui saat hamil seperti paritas dan jarak kelahiran dan ini merupakan factor risiko yang tergolong kelompok I atau Ada Potensi Gawat Obstetrik/APGO pada skor poedji, sedangkan riwayat komplikasi kehamilan didalam skor poedji rochjati termasuk di kelompok II dan III atau Ada Gawat Obstetrik (AGO) dan Ada Gawat Darurat Obstetrik (ADGO). 
Dinamika Kesehatan Jurnal Kebidanan dan Keperawatan Vol 10 No. 1 Juli 2019 ( ISSN: 2086-3454 EISSN: 2549-4058)

url: http://ojs.dinamikakesehatan.unism.ac.id DOI : https://doi.org/10.33859/dksm.v10i2

Cara Persalinan Dan Terjadinya Komplikasi Persalinan Berdasarkan Tingkat Risiko Kehamilan Menurut Skor Poedji Rochjati Di Praktik Mandiri Bidan F Banjarmasin

Komplikasi persalinan yang di dapatkan pada penelitian ini adalah kala II lama, kala Fase aktif memanjang, persalinan dengan hipertensi, retensio placenta dan perdarahan post partum. Ibu yang mengalami komplikasi persalinan ini adalah ibu yang saat hamil tergolong pada kehamilan risiko sangat tinggi dan risiko tinggi. Sebagai contoh, ibu yang saat hamil mengalami anemia sedang, pada saat persalinan mengalami kontraksi yang kurang baik (Inertia uteri) sehingga membuat persalinan menjadi lama. Contoh kasus yang lain yang terjadi pada ibu yang menjadi sampel penelitian ini ibu hamil yang berusia 42 tahun, saat kala II mengalami kelelahan dan tidak mampu mengedan sehingga kala II menjadi lama dan harus berakhir dengan persalinan buatan.

Komplikasi persalinan dapat terjadi pada sebagian ibu hamil. Besarnya kemungkinan terjadinya komplikasi pada ibu hamil tidak sama, tergantung 0vbeadaan saat kehamilan, apakah ibu tersebut tanpa masalah (kelompok ibu hamil risiko rendah) ataukah ibu tersebut mempunyai masalah (Kelompok ibu hamil risiko tinggi dan risiko sangat tinggi). Ibu hamil risiko tinggi dan sangat tinggi perlu mendapatkan perhatian untuk melakukan pencegahan dan pengenalan dini terjadinya komplikasi persalinan dan selanjutnya jika memang terjadi komplikasi maka dapat ditemukan dini dan segera diberikan penanganan (Rochjati, 2011)

Mengingat pentingnya pengenalan dan penanganan dini komplikasi dalam kehamilan dan persalinan dan adanya hubungan tingkat risiko kehamilan dan kejadian komplikasi persalinan, maka peneliti menyarankan untuk selalu menggunakan skor poedji rochjati ini pada semua ibu hamil dan juga perlu dikenalkan kepada keluarga ataupun kader mengenai factor risiko yang dapat ditemui pada ibu hamil. 
Dinamika Kesehatan Jurnal Kebidanan dan Keperawatan Vol 10 No. 1 Juli 2019 ( ISSN: 2086-3454 EISSN: 2549-4058)

url: http://ojs.dinamikakesehatan.unism.ac.id DOI : https://doi.org/10.33859/dksm.v10i2

Cara Persalinan Dan Terjadinya Komplikasi Persalinan Berdasarkan Tingkat Risiko Kehamilan Menurut Skor Poedji Rochjati Di Praktik Mandiri Bidan F Banjarmasin

\section{UCAPAN TERIMA KASIH}

Terima kasih kami ucapkan kepada Rektor Universitas Sari Mulia yang telah memberikan dukungan kepada peneliti. Terimakasih juga kami ucapkan kepada Bidan F yang yang telah memfasilitasi tempat penelitian

\section{DAFTAR PUSTAKA}

Alimul, Azis. 2007. Metode Penelitian Keperawatan dan Teknik Analisa Data. Jakarta: Salemba Medika.

Deprika, dkk. 2017. Factor Yang Berhubungan Dengan Kejadian Anemia Pada Ibu Hamil Di Puskesmas Mantrijeron Yogyakarta. Yogyakarta : Universitas Aisyiyah.

Hidayah, dkk, 2018. Hubungan Tingkat Risiko Kehamilan dengan Kejadian Komplikasi Persalinan di RSUD Panembahan Senopati Bantul. Jurnal Kesehatan Vocasional Vol 3 No 1

JNPK-KR, 2012. Asuhan Persalinan Normal, Asuhan Essensial Bagi Ibu Bersalinan dan Bayi Baru Lahir Serta Penatalaksanaan Komplikasi Sera Pasca Persalinan dan Nifas. Jakarta : JNPK KR

Legawati, 2018. Asuhan Persalinan dan Bayi Baru Lahir. Malang : Wineka Media

Muthmainnah, dkk. 2017. Asuhan Persalinan Normal dan Bayi Baru Lahir. Yogyakarta : Penerbit ANDI.

Oktarina, Mika. 2016. Buku Ajar Asuhan Kebidanan Persalinan dan Bayi Baru Lahir. Yogyakarta : Deepublish.
Prawirohardjo, Sarwono. 2013. Ilmu Kebidanan. Jakarta: YBP - SP.

Poedji Rochjati, 2011. Skrining Antenatal pada Ibu Hamil Edisi 2 Pengenalan Factor Risiko. Airlangga university press.

Poedji Rochjati, 2003. Rujukan terencana dala system rujukan paripurna Terpadu Kabupaten/Kota. Surabaya : Airlangga university press.

Pusat informasi data. 2014. Infodatin, Mothers day, Kondisi Kesehatan Ibu. Jakarta : Kemenkes RI

Rizkinauli, Raisah Amalia, 2016. Analisis Faktor Penyebab Komplikasi Obstetric Pada Ibu Bersalin Di Rumah Sakit Umum PKU Muhammadiyah Bantul. Yogyakarta: Fakultas Ilmu Kesehatan.

Senewe, felly. 2004. Faktor yang berhubungan dengan komplikasi persalinan di Tiga Tahun Terakhir. Penel kesehatan, volume 23.

Simarmata, 2014. Determinan Kejadian Komplikasi Persalinan Di Indonesia: Analisis Data Sekunder Riset Kesehatan Dasar 2010. Jurnal Kesehatan Reproduksi. Volume 5.

Sudarma, Momon. 2008. Sosiologi Kesehatan. Jakarta : Salemba Medika. . 2017. Profil Kesehatan Indonesia. Jakarta : KEMENKES RI 